\title{
Pathological Sprouting of Adult Nociceptors in Chronic Prostate Cancer-Induced Bone Pain
}

\author{
Juan M. Jimenez-Andrade, ${ }^{1}$ Aaron P. Bloom, ${ }^{1}$ James I. Stake, ${ }^{1}$ William G. Mantyh, ${ }^{1}$ Reid N. Taylor, ${ }^{1}$ Katie T. Freeman, ${ }^{3}$ \\ Joseph R. Ghilardi, ${ }^{3}$ Michael A. Kuskowski, ${ }^{4}$ and Patrick W. Mantyh ${ }^{1,2,3}$ \\ ${ }^{1}$ Department of Pharmacology, College of Medicine, and ${ }^{2}$ Arizona Cancer Center, University of Arizona, Tucson, Arizona 85724, and ${ }^{3}$ Research Service and \\ ${ }^{4}$ Geriatric Research Education and Clinical Centers, Veterans Affairs Medical Center, Minneapolis, Minnesota 55417
}

\begin{abstract}
Pain frequently accompanies cancer. What remains unclear is why this pain frequently becomes more severe and difficult to control with disease progression. Here we test the hypothesis that with disease progression, sensory nerve fibers that innervate the tumor-bearing tissue undergo a pathological sprouting and reorganization, which in other nonmalignant pathologies has been shown to generate and maintain chronic pain. Injection of canine prostate cancer cells into mouse bone induces a remarkable sprouting of calcitonin gene-related peptide $\left(\mathrm{CGRP}^{+}\right)$and neurofilament $200 \mathrm{kDa}\left(\mathrm{NF} 200^{+}\right)$sensory nerve fibers. Nearly all sensory nerve fibers that undergo sprouting also coexpress tropomyosin receptor kinase $\mathrm{A}\left(\mathrm{TrkA}^{+}\right)$. This ectopic sprouting occurs in sensory nerve fibers that are in close proximity to colonies of prostate cancer cells, tumor-associated stromal cells and newly formed woven bone, which together form sclerotic lesions that closely mirror the osteoblastic bone lesions induced by metastatic prostate tumors in humans. Preventive treatment with an antibody that sequesters nerve growth factor (NGF), administered when the pain and bone remodeling were first observed, blocks this ectopic sprouting and attenuates cancer pain. Interestingly, reverse transcription PCR analysis indicated that the prostate cancer cells themselves do not express detectable levels of mRNA coding for NGF. This suggests that the tumor-associated stromal cells express and release NGF, which drives the pathological reorganization of nearby $\operatorname{TrkA}^{+}$ sensory nerve fibers. Therapies that prevent this reorganization of sensory nerve fibers may provide insight into the evolving mechanisms that drive cancer pain and lead to more effective control of this chronic pain state.
\end{abstract}

\section{Introduction}

World health experts estimated that in 2008 there were $>12$ million new cases of cancer diagnosed and 7.6 million deaths from cancer (Boyle and Levin, 2008). Despite the increasing prevalence of cancer, improvements in the detection and treatment of the disease have dramatically increased survival rates so that even patients with metastatic bone cancer are living years beyond their initial diagnosis (Jemal et al., 2009). For example, in the United States, men with prostate cancer that has already metastasized to bone currently have a median survival time of 53 months (Rigaud et al., 2002). Unfortunately, cancer-associated pain can be present at any time during the course of the disease, but the frequency and intensity of cancer pain tends to increase with advancing stages of cancer (Mercadante and Arcuri, 1998). Thus, it has been reported that $75-90 \%$ of patients with metastatic or advanced stage cancer will experience significant cancer-induced pain (Berruti et al., 2000; Meuser et al., 2001).

Once prostate cancer cells have metastasized to the skeleton, tumor-induced bone pain frequently follows (Berruti et al., 2000;

Received June 25, 2010; revised Aug. 9, 2010; accepted Sept. 1, 2010.

This work was supported by the National Institutes of Health (Grant NS23970), by the Department of Veterans Affairs, Veterans Health Administration, Rehabilitation Research and Development Service Grants (04380-I and A6707-R), and by the Calhoun Fund for Bone Pain.

Correspondence should be addressed to Dr. Patrick W. Mantyh, Department of Pharmacology, College of Medicine, University of Arizona, 1656 East Mabel, Room 119, P.0. Box 245215, Tucson, AZ 85724. E-mail: pmantyh@email.arizona.edu.

DOI:10.1523/JNEUROSCI.3300-10.2010

Copyright $\odot 2010$ the authors $\quad 0270-6474 / 10 / 3014649-08 \$ 15.00 / 0$
Dy et al., 2008). Prostate cancer-induced bone pain is usually described as dull in character, constant in presentation, and gradually intensifying with time (Dy et al., 2008; Rajarubendra et al., 2010). However, as the prostate tumor grows, a second type of pain known as breakthrough pain begins to occur. This pain is known as such because it "breaks through" the analgesic regimen the patient is receiving to control the ongoing pain (Portenoy and Hagen, 1990; Hwang et al., 2003) and is frequently divided into two types: a "spontaneous pain" that occurs without any obvious precipitating event and a "movement-evoked pain" precipitated by movement of the tumor-bearing bone (Portenoy and Hagen, 1990; Mercadante et al., 2004). These breakthrough pains are generally more severe and unpredictable than ongoing cancer pain (Mercadante et al., 2004), and as such can be highly debilitating to the patient's functional status and quality of life (Weinfurt et al., 2005), resulting in a significant increase in healthcare utilization.

Breakthrough cancer pain appears to be different from ongoing pain in terms of onset, precipitating events, and severity. However, a largely unanswered question is whether this pain is simply a more severe ongoing pain or whether it is largely driven by a different mechanism(s) and/or a newly formed neurological substrate not originally present when ongoing cancer pain first occurs. Previous studies have suggested that ectopic sprouting and/or pathological remodeling of sensory nerve fibers can drive difficult to control human pain states such as painful neuromas (due to injury or transection of a peripheral nerve) (Lindqvist et al., 2000; Black et al., 2008) or complex regional pain syndrome 
(where the most common precipitating event is bone fracture) (Jänig and Baron, 2003; de Mos et al., 2007). The present study explores whether prostate cancer cells can induce an active and pathological sprouting/reorganization of specific populations of sensory nerve fibers, what factor(s) drive this sprouting/reorganization, and whether therapeutic intervention can attenuate this sprouting/reorganization and the accompanying pain.

\section{Materials and Methods}

Mice. Experiments were performed using 70 adult male athymic nude mice ( $8-10$ weeks old; Harlan Laboratories), weighing $20-32 \mathrm{~g}$. The mice were housed in accordance with the NIH guidelines under specific pathogen-free conditions in autoclaved cages maintained at $22^{\circ} \mathrm{C}$ with a $12 \mathrm{~h}$ alternating light and dark cycle and were given autoclaved food and water ad libitum. All procedures were approved by the Institutional Animal Care and Use Committee at the University of Arizona (Tucson, AZ) and VA Medical Center (Minneapolis, MN).

Culture and injection of tumor cells. Canine prostate carcinoma (ACE-1) cells were stably transfected with green fluorescent protein (GFP), cultured and injected into the intramedullary space as previously described (Halvorson et al., 2005). Briefly, following induction of general anesthesia with ketamine/xylazine $(100 / 5 \mathrm{mg} / \mathrm{kg}$, i.p.), an arthrotomy was performed exposing the condyles of the distal femur. The bone was cored with a 30 gauge needle inserted at the level of the intercondylar notch. The coring needle was then replaced with a 29 gauge hypodermic needle used to inject either HBSS as the control (Sigma; $20 \mu \mathrm{l}$ ) or HBSS containing $10^{5}$ ACE-1 cells $(20 \mu \mathrm{l})$ into the intramedullary space. To prevent cell reflux following injection, the injection site was sealed with dental grade amalgam (Dentsply) using an endodontic messing gun (Union Broach), followed by copious irrigation with sterile filtered water (hypotonic solution). Wound closure was achieved using a single $7 \mathrm{~mm}$ auto wound clip (Becton Dickinson). Day 26 after cell injection was chosen as the date of death, as by this time there was an extensive formation of cancer cell colonies, formation of woven bone in the tumorbearing bone, as well as significant pain behaviors.

Treatment with anti-nerve growth factor antibody. The anti-nerve growth factor (NGF) sequestering antibody (mAb 911), kindly provided by Dr. David Shelton (Rinat/Pfizer), is effective in blocking the binding of NGF to both TrkA (tropomyosin receptor kinase A) and p75 NGF receptors and inhibiting TrkA autophosphorylation (Hongo et al., 2000). The anti-NGF antibody possesses a plasma half-life of $\sim 5-6 \mathrm{~d}$ in the mouse and it does not appreciably cross the blood brain barrier (Shelton et al., 2005). The dose used ( $10 \mathrm{mg} / \mathrm{kg}$, i.p.) was based on previous studies (Halvorson et al., 2005; Sevcik et al., 2005). Therapy was initiated either when cancer-induced pain behaviors were first evident (day 10) or after significant disease progression had occurred (day 24). Prostate cancerinjected mice were divided into 4 groups: prostate cancer + vehicle, prostate cancer + early/acute anti-NGF (administered at day 10 after cell injection), prostate cancer + early/sustained anti-NGF treatment (administered at days 10, 15, 20 and 25 after cell injection) and prostate cancer + late/acute anti-NGF treatment (administered at day 24 after cell injection). To compare the magnitude of the analgesic effect between the groups, the number of spontaneous flinches was expressed as percentage reduction of pain, where $100 \%$ was the total number of flinches that was present in the prostate cancer + vehicle group over a 2 min observation period. The general health of the mice was closely monitored using food consumption and body weight as general health indicators throughout the experiments.

Pain behaviors. Mice were behaviorally tested at days 12, 17,23, 24, and 26 after cell or HBSS (vehicle) injection. Mice were placed in a clear plastic observation box with a wire mesh floor and allowed to habituate for a period of $30 \mathrm{~min}$. After acclimation, the number of spontaneous flinches of the tumor-bearing limb were recorded over a 2 min observation period (Sabino et al., 2002; Halvorson et al., 2005). Flinches were defined as holding of the hindpaw aloft while not ambulatory.

Euthanasia and micro-computed tomography $(\mu C T)$ analysis. Mice were killed with $\mathrm{CO}_{2}$ delivered via compressed gas cylinder and perfused intracardially with $20 \mathrm{ml}$ of $0.1 \mathrm{MPBS}\left(\mathrm{pH}=7.4\right.$ at $\left.4^{\circ} \mathrm{C}\right)$ followed by $20 \mathrm{ml}$ of $4 \%$ formaldehyde $12.5 \%$ picric acid solution in $0.1 \mathrm{M} \mathrm{PBS} \mathrm{(} \mathrm{pH}=6.9$ at $4^{\circ} \mathrm{C}$ ). Mouse femurs were removed, postfixed for $4 \mathrm{~h}$ in the perfusion fixative and placed in PBS solution at $4^{\circ} \mathrm{C}$. To characterize the cancerinduced changes in mineralized bone micro-architecture, femurs were analyzed with an eXplore Locus SP micro-computed tomographer $(\mu \mathrm{CT})($ GE Healthcare). This conebeam $\mu \mathrm{CT}$ scanner uses a $2300 \times 2300$ CCD detector with current and voltage set at $80 \mu \mathrm{A}$ and $80 \mathrm{KV}$, respectively. Specimens were scanned in 1080 views through $360^{\circ}$ with a 2100 $\mathrm{ms}$ integration time. Scans were then reconstructed at $16 \mu \mathrm{m}^{3}$ resolution using Reconstruction Utility software (GE Healthcare) and visualized with Microview software (GE Healthcare).

Immunohistochemistry. Femurs were processed for immunohistochemistry as frozen sections through the bone. Once $\mu \mathrm{CT}$ analysis was performed, mouse femurs were decalcified in 10\% EDTA ( 2 weeks) with the extent of decalcification being regularly monitored with high resolution Faxitron analysis. Once decalcification had occurred, the bones were cryoprotected in $30 \%$ sucrose and serially sectioned along the longitudinal axis, in the coronal plane, at a thickness of $20 \mu \mathrm{m}$ as previously described. Bone sections were mounted on gelatin-coated slides, dried at room temperature for $30 \mathrm{~min}$, blocked with $3 \%$ normal donkey serum (NDS) and $0.3 \%$ Triton X-100 in PBS for $1 \mathrm{~h}$ and incubated with primary antibodies overnight. Primary antibodies were made in a solution of $1 \%$ NDS and $0.1 \%$ Triton X-100 in PBS. Peptide-rich sensory nerve fibers were labeled with rabbit anti-CGRP $(1: 12,000$; Sigma, cata$\log$ \# C8198). Sensory nerve fibers expressing the $200 \mathrm{kDa}$ neurofilament (NF200) were labeled with an antibody against NF200 (anti-chicken, 1:5000; Neuromics, catalog \# CH22104). Sprouted nerve fibers were labeled with an antibody against growth associated protein-43 (GAP-43) (rabbit anti-GAP43, 1:1000; Millipore, catalog \# AB5220). Nerve fibers expressing TrkA were labeled with goat anti-TrkA (1:50, R\&D Systems, catalog \# AF1056). Macrophages and osteoclasts were labeled with a monocyte marker (rat anti-mouse CD68, 1:500, Serotec, catalog \# MCA1957). Sensory and sympathetic nerve fibers were labeled with a pan-neuronal marker (PGP 9.5; 1:4000, Ultraclone; catalog \# RA95101). Blood vessels were labeled with a marker of endothelial cells present in blood vessels (Odaka et al., 2006; Kivelä et al., 2007) (monoclonal rat anti-mouse CD31, 1:500, BD PharMingen, catalog \# 550274). Since endogenous GFP signal from cancer cells was visualized in the green channel, preparations were then incubated with $\mathrm{Cy} 3-$ or Cy5-conjugated secondary antibodies (1:600 and 1:400, respectively, Jackson ImmunoResearch) for $1 \mathrm{~h}$. Preparations were then washed with PBS three times and counterstained with DAPI (4', 6-diamidino-2-phenylindole, dihydrochloride, 1:30,000; Invitrogen) for $5 \mathrm{~min}$ and washed with PBS. Finally, tissue was dehydrated through an alcohol gradient $(70,80,90$, and $100 \%$ ), cleared in xylene, and coverslipped with di- $n$-butylphthalatepolystyrene-xylene (Sigma). Preparations were allowed to dry at room temperature for $12 \mathrm{~h}$ before imaging.

Laser confocal microscopy. Images used for illustration purposes were acquired with an Olympus Fluoview FV1000 and Carl Zeiss LSM 700 systems that are equipped with multiple lasers and excitation and emission fluorescence filters. The endogenous GFP signal emitted from the prostate cancer cells did not require amplification for analysis. Sequential acquisition mode was used to reduce bleed-through from fluorophores. Images were then processed with Adobe Photoshop CS and assembled into figures with Adobe Illustrator CS4.

Quantification of the density of sensory nerve fibers. For quantification purposes, longitudinal section images of the whole bone ( 2 bone sections per animal) were taken with a Carl Zeiss LSM 700 confocal system that is equipped with a computer-controlled motorized stage. For quantifying a particular marker, each longitudinal section used for quantification was distant from the other longitudinal section by at least $0.1 \mathrm{~mm}$. Density of nerve fiber per volume was obtained by determining the total length of nerve fibers using the curve spline tool (Axio Vision, v.4.8; Carl Zeiss) within the total area where GFP cancer cells were present. This result was then multiplied by the thickness of the longitudinal section (Yen et al., 2006).

Evaluation of disease progression. Effect of anti-NGF therapy on disease progression was evaluated by performing $\mu \mathrm{CT}$ and radiographic analysis. Additionally, the number of cancer cell colonies in bone from tumorbearing mice treated with vehicle or early/sustained anti-NGF was deter- 
mined. A cancer cell colony was defined as a cluster of $\mathrm{GFP}^{+}$prostate cancer cells that had a diameter from 0.3 to $2.3 \mathrm{~mm}$ mostly surrounded by woven bone.

Quantification of the percentage of stromal cells within a cancer cell colony. In longitudinal sections of mouse bones, randomly selected prostate cancer colonies were used to determine the total number of stromal cells by calculating the percentage of $\mathrm{GFP}^{+}$prostate cancer cells per total number of $\mathrm{DAPI}^{+}$nuclei within the colony.

Reverse transcription PCR analysis of mRNA levels of nerve growth factor in the prostatic ACE-1 cell line. Total RNA from dog brain tissue samples or cultured ACE-1 prostate cells were prepared using the RNeasy micro kit (Qiagen), and the RNA was quantified using Ribogreen reagent (Invitrogen). Two-step reverse transcription (RT)-PCR was done using the TaqMan Gold RT-PCR kit (Applied Biosystems). The RNA was reverse-transcribed using random hexamers, and the $C D N A$ was amplified using a primer/probe set specifically for canine NGF (AACAGGACTCACAGGAGCAA, CGGCACTTGGTCTCAAAGAA, and AATGTTCACCTCTCCCAGCACCATCA). The samples were analyzed in duplicate from the reversetranscription step and normalized to total RNA input.

Statistical analysis. Data are presented as mean \pm SEM. The SPSS statistics package (v. 12) was used to perform statistical tests. Immunohistochemical and pain behavioral data were analyzed across treatment groups using a Kruskal-Wallis nonparametric ANOVA. Significant main effects of groups were followed by Mann-Whitney nonparametric $t$ tests with Bonferroni adjustment for multiple comparisons. Significance level was set at $p<0.05$. The individual investigator responsible for behavior, immunohistochemical analysis, and scoring bone remodeling was blind to the experimental conditions of each animal.

\section{Results}

The mouse model of prostate cancer-induced bone pain

In the present study, we use a prostate cancer pain model that involves injecting and confining $\mathrm{GFP}^{+}$canine prostate tumor cells into the marrow space of the mouse femur and allowing the tumor cells to grow and remodel bone over a $26 \mathrm{~d}$ period. Radiographic analyses showed that, in mice, these canine prostate cancer cells induced bone-forming cancerous foci, which appear as nodular, rounded, and fairly well circumscribed sclerotic areas due the to production of woven bone (data not shown). Micro-CT analysis indicated that bones from sham mice (needle placement + injection of culture medium) did not display significant bone remodeling (Fig. $1 A$ ) compared with naive mice (data not shown). In contrast, $\mu \mathrm{CT}$ analysis along with immunohistochemical analysis revealed that mouse femurs injected with $\mathrm{GFP}^{+}$canine osteoblastic prostate cancer cells contained small prostate tumor cell colonies throughout the bone marrow that were surrounded by matrices of new woven bone (Fig. $1 B, C$ ). The tumor-induced bone formation of cancer cell colonies was dependent on disease progression. While animals at early time points of the disease show one cancer cell colony/per femur (Fig. $1 B$ ), tumor-bearing femurs at advanced stages of the disease had $6.8 \pm 1.8$ cancer cell colonies per femur (Fig. $1 C$ ).

Immunohistochemical analysis was performed to further define the cell types and their viability in the colonies of prostate cancer cells in the mouse bone. Confocal analysis showed a high association of prostate cancer cells with macrophages (Fig. $2 B$ ), which were unique in morphology and location, and appeared to be significantly larger than macrophages in normal marrow (Fig. $2 A)$. Furthermore multinucleated osteoclasts decorated the interface of the tumor/woven bone (Fig. $2 \mathrm{~B}$ ). Within the colonies of canine prostate cancer cells there appeared to be an increased vascularization compared with the normal marrow space. Thus, prostate tumor-bearing femurs (day 26 after cell injection) were evaluated and it was shown that the colonies of osteoblastic tumor cells were not only highly vascularized (Fig. 2D) but the

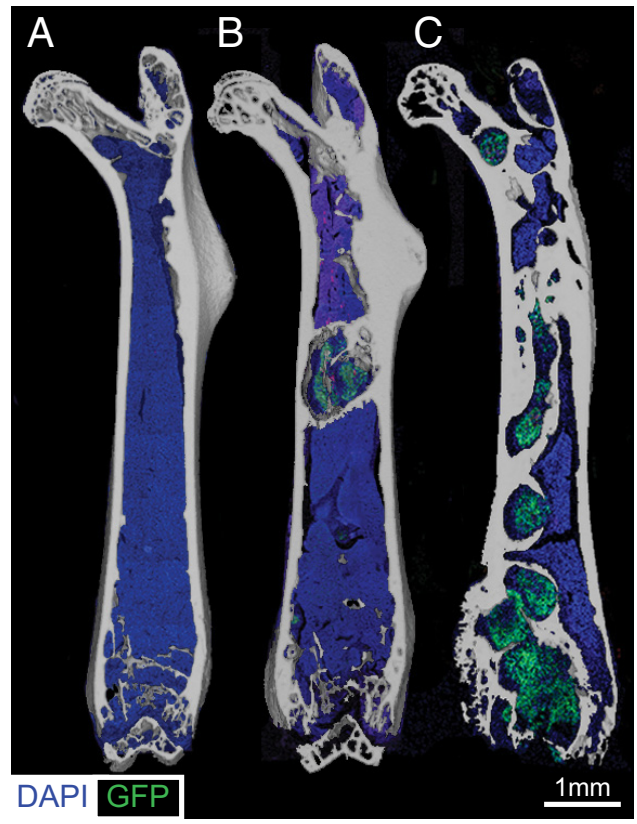

Figure 1. Prostate cancer cells induce osteoblastic lesions in the mouse femur which closely mirror the osteoblastic lesions observed in patients with prostate cancer metastases to the bone. $\boldsymbol{A}-\boldsymbol{C}$, A low-power $\mu \mathrm{CT}$ cross section (100 $\mu \mathrm{m}$ thick) of a sham $(\boldsymbol{A})$ and prostate cancer cell-injected femur from mice killed at early-stage $(\boldsymbol{B})$ and late-stage disease $(\boldsymbol{C})$. These $\mu \mathrm{CT}$ images were overlaid on confocal images ( $20 \mu \mathrm{m}$ thick) of cell nuclei (DAPI, blue) and prostate cancer cells stably transfected with GFP of the same bone. As the GFP ${ }^{+}$tumor cells (green) grow in normal bone marrow (the normal tightly packed hematopoietic cells, blue) they induce the formation of woven bone around the colony, eventually forming an osteoblastic lesion. Note that these osteoblastic lesions are not present in the sham femur and increase in number with disease progression.

tumor-associated blood vessels were different from those that vascularize normal marrow (Fig. 2C) in terms of their increased diameter, and jagged, nonlinear morphology.

Sprouting and organization of sensory nerve fibers in the marrow of the normal and prostate tumor-bearing bone To examine the effects of prostate tumor growth on sensory innervation of the marrow, bone sections from naive, sham and mice injected with $\mathrm{GFP}^{+}$prostate cancer cells were labeled with an antibody raised against CGRP. In comparing the organization and density of $\mathrm{CGRP}^{+}$nerve fibers in the bone marrow of naive versus sham mice (Fig. 3A), there appeared to be no difference in the organization or density of $\mathrm{CGRP}^{+}$nerve fibers (data not shown). Confocal images showed that these nerve fibers mainly run along the long axis of the bone as single nerve fibers with a largely linear morphology (Fig. 3A). In contrast, in tumorbearing mice at $26 \mathrm{~d}$ after tumor cell injection, $\mathrm{CGRP}^{+}$nerve fibers in the tumor cell colonies showed significant sprouting, an increase in nerve fiber density and a highly disorganized appearance (Fig. $3 B, C$ ).

In addition to $\mathrm{CGRP}^{+}$nerve fibers, we observed similar aberrant sprouting and reorganization in the sensory nerve fibers that express NF200. These sprouting CGRP ${ }^{+}$and NF200 ${ }^{+}$nerve fibers appeared to be intermingled among $\mathrm{GFP}^{+}$tumor cells and the stromal cells that comprise the tumor cell colonies (Fig. $4 A-D$; supplemental Fig. 1, available at www.jneurosci.org as supplemental material). It should be stressed that in previous studies in our laboratory and in the present study, we have never observed $\mathrm{CGRP}^{+}$or $\mathrm{NF} 200^{+}$nerve fibers in the marrow space 

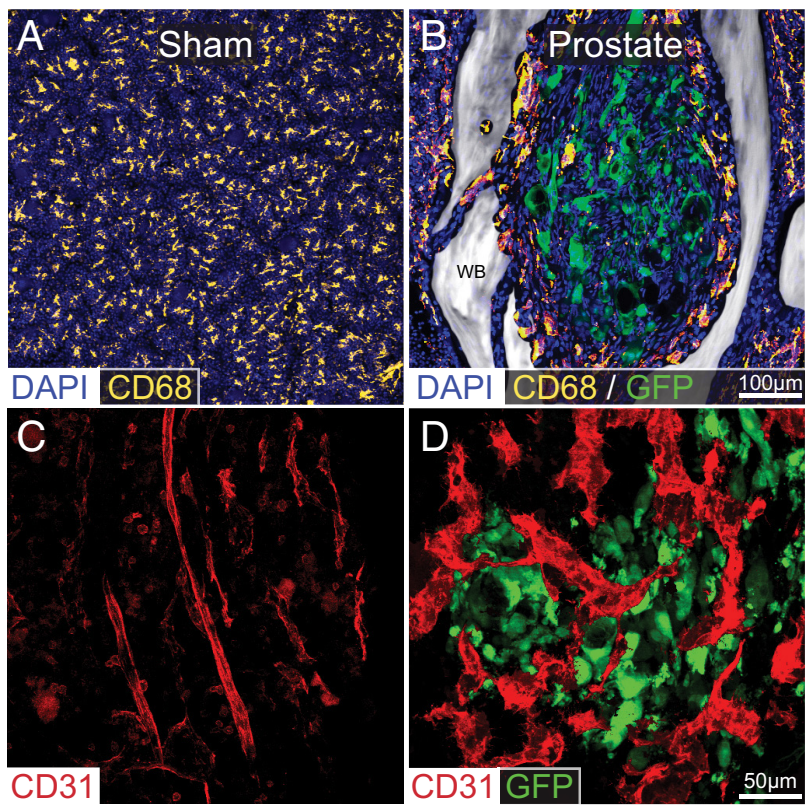

Figure 2. Colonies of prostate cancer cells in bone are characterized by viable cancer cells, a rich, although irregular, vascular supply and newly formed woven bone which demarcates the outer perimeter of the colony. $\boldsymbol{A}-\boldsymbol{D}$, Confocal images of bone sections ( $20 \mu \mathrm{m}$ thick) from sham mice $(\boldsymbol{A}, \boldsymbol{C})$ or mice $26 \mathrm{~d}$ after injection of GFP ${ }^{+}$prostate cancer cells $(\boldsymbol{B}, \boldsymbol{D})$. The bone marrow in sham-injected animals looks the same as in naive animals and is filled with densely packed $\mathrm{DAPI}^{+}$cell bodies of mostly hemopoetic cells (blue) and $\mathrm{CD} 68^{+}$macrophages (yellow) $(\boldsymbol{A})$. In contrast, when $\mathrm{GFP}^{+}$prostate tumor cells grow within the bone $(\boldsymbol{B}, \boldsymbol{D})$ the colonies of GFP ${ }^{+}$ prostate cancer cells form small colonies characterized by GFP ${ }^{+}$cancer cells (green), enlarged $\mathrm{CD}^{+}{ }^{+}$macrophages and osteoclasts (yellow) and adjacent tumor-induced formation of w0ven bone (WB, white) $(\boldsymbol{B})$. To visualize woven bone $(\boldsymbol{B})$, a differential interphase contrast image was taken after acquiring a confocal image of the same section. Note that $\mathrm{CD} 68{ }^{+}$macrophages that associate with cancer cells $(\boldsymbol{B})$ are significantly larger compared with macrophages in sham animals $(\boldsymbol{A})$. Additionally, these cancer cell colonies are highly vascularized by $\mathrm{CD} 31^{+}$blood vessels (red) and the morphology and size of blood vessels within the tumor colony $(\boldsymbol{D})$ is highly heterogeneous and disorganized compared with blood vessels in the bone marrow of sham mice (C).

with such a high density and disorganized appearance in naive or sham-treated mice (Mach et al., 2002; Halvorson et al., 2005; Peters et al., 2005; Martin et al., 2007; Jimenez-Andrade et al., 2010)
To begin to determine more specifically the phenotype of sprouting nerve fibers, bone sections from animals injected with canine prostate cancer cells were double-labeled with CGRP, NF200, TrkA and/or GAP43. Using double- and triple-label immunohistochemistry, we examined whether the sprouting $\mathrm{CGRP}^{+}$or NF $200^{+}$populations of sensory nerve fibers colocalize with the cognate receptor for NGF (TrkA) or GAP43, which is a protein involved in the growth of new nerve fibers in both developing and adult animals (Denny, 2006). In the tumor-bearing bone, quantitative analysis revealed that $>90 \%$ of the sprouting CGRP $^{+}$ and $\mathrm{NF}_{200^{+}}$nerve fibers coexpressed TrkA (Fig. 4; supplemental Fig. 1, available at www.jneurosci.org as supplemental material). Double-labeled nerves for TrkA and GAP43 demonstrated that in prostate tumor-bearing mice, the great majority of $\mathrm{TrkA}^{+}$nerve fibers that had undergone sprouting also expressed high levels of GAP43 (supplemental Fig. 2A,B).

\section{Effects of anti-NGF therapy on sensory nerve fibers in the marrow, prostate cancer-induced pain, and cancer progression}

To determine the percentage of nerve fibers in the bone that express TrkA, we double-labeled bone sections with the panneuronal marker PGP 9.5 and TrkA. As can be seen in supplemental Figure 3 (available at www.jneurosci.org as supplemental material), the great majority of PGP $9.5^{+}(>80 \%)$ nerve fibers in bone coexpress TrkA. In sham mice treated from day 10-26 with anti-NGF (Fig. $5 A, D$ ), the linear organization and density of $\mathrm{CGRP}^{+}$and NF200 ${ }^{+}$sensory nerve fibers were unchanged and were similar to the density and organization found in naive mice (data not shown). In contrast, significant ectopic sprouting of CGRP $^{+}$(Fig. 5B) and NF200 ${ }^{+}$nerve fibers (Fig. 5E) was observed in prostate tumor-bearing femurs at $26 \mathrm{~d}$ after cell injection. Quantitative analysis revealed that early/sustained treatment with antiNGF (given at 10, 15, 20, and $25 \mathrm{~d}$ after tumor injection) prevented the sprouting of CGRP ${ }^{+}$(Figs. 5C, 6A) and NF200 ${ }^{+}$(Figs. 5F, 6B) nerve fibers. Interestingly, the attenuation of this sprouting was observed only with the early/sustained anti-NGF administration and not with the late/acute administration (given at day 24 after cell injection) (Fig. 6A, $B$ ).

Additionally, early/sustained treatment with anti-NGF also significantly attenuated the sprouting of $\mathrm{GAP} 43^{+} / \mathrm{TrkA}^{+}$nerve
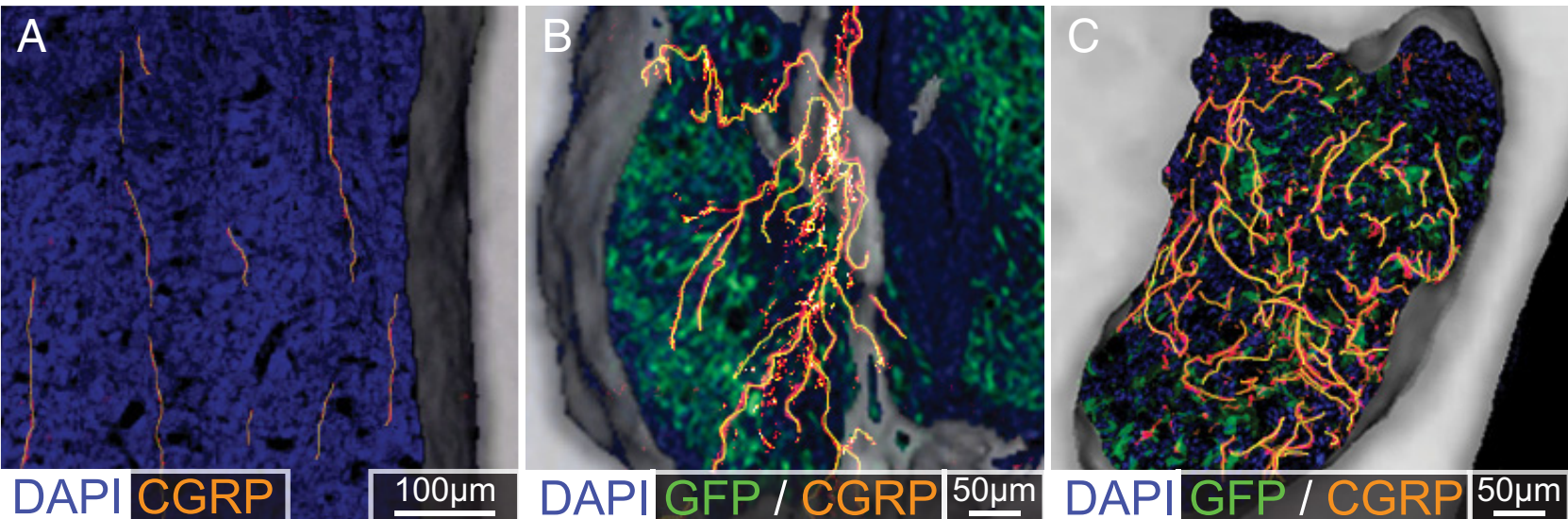

Figure 3. Prostate cancer cells induce sprouting of sensory nerve fibers. $\boldsymbol{A}-\boldsymbol{C}$, High-power $\mu$ CT cross sections of bone ( $100 \mu \mathrm{m}$ thick) overlaid with confocal images ( $20 \mu \mathrm{m}$ thick) of a sham femur $(\boldsymbol{A})$ and tumor-bearing femur from mice killed at early $(\boldsymbol{B})$ and more advanced stages of the disease $(\boldsymbol{C})$. In these images the DAPI stained nuclei appear blue, the GFP-expressing prostate cancer cells appear green and the $\mathrm{CGRP}^{+}$sensory nerve fibers appear yellow/red. Note that in the sham mice, $\mathrm{CGRP}^{+}$nerve fibers that are present in the marrow space appear as single nerve fibers with a highly linear morphology. As GFP ${ }^{+}$prostate tumor cells proliferate and form tumor colonies $(\boldsymbol{B}, \boldsymbol{C})$, the $\mathrm{CGRP}^{+}$sensory nerve fibers undergo marked sprouting which produces highly branched sensory nerve fibers $(\boldsymbol{B})$ and a high density of sensory nerve fibers $(\boldsymbol{C})$ that is never observed in the normal marrow $(\boldsymbol{A})$. 


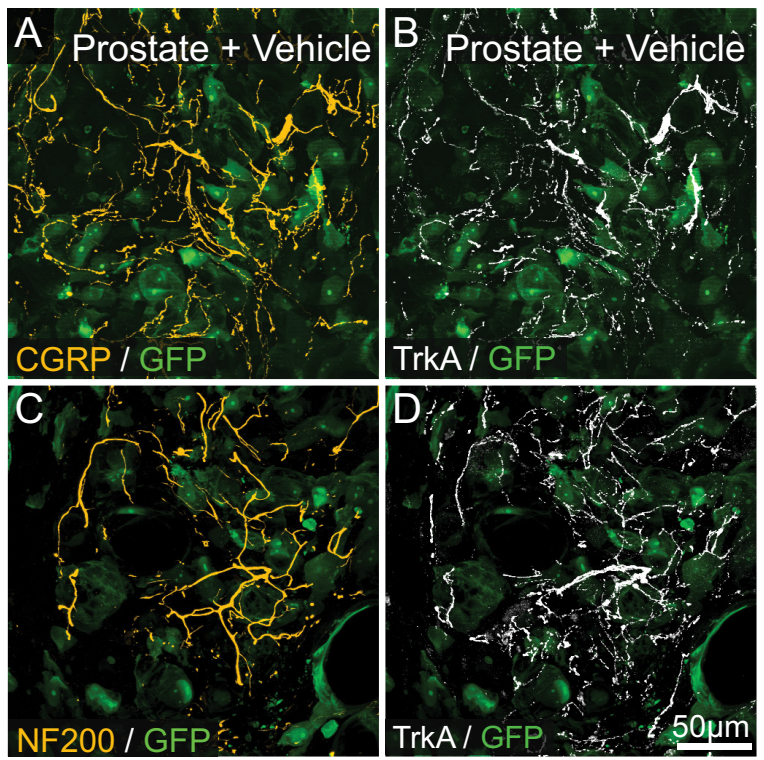

Figure 4. $\mathrm{CGRP}^{+}$and $\mathrm{NF}^{200}{ }^{+}$sensory nerve fibers that undergo tumor-induced nerve sprouting coexpress TrkA. A-D, Representative confocal images of GFP ${ }^{+}$cancer colonies (green) in mouse bone sections (20 $\mu \mathrm{m}$ thick) that have been colabeled for CGRP (a marker of peptidergic-rich sensory nerve fibers, orange) $(\boldsymbol{A})$ and TrkA (the cognate receptor for NGF, white) (B). Representative confocal images of GFP ${ }^{+}$cancer colonies (green) from mouse bone sections ( $20 \mu \mathrm{m}$ thick) that have been simultaneously colabeled for neurofilament 200 (NF200), which is a marker of myelinated sensory nerve fibers, orange) $(\boldsymbol{C})$ and TrkA (white) (D). Note that the great majority of $\mathrm{CGRP}^{+}$and $\mathrm{NF}^{200}{ }^{+}$nerve fibers that have undergone sprouting and have a disorganized appearance also express TrkA. Images were acquired using cross-sections and were projected from 40 optical sections at $0.5 \mu \mathrm{m}$ intervals. fibers (supplemental Fig. 2C,D). Importantly, early/sustained administration of anti-NGF did not affect the organization or density of CGRP ${ }^{+}$and $\mathrm{NF}_{200}{ }^{+}$in the contralateral, non-tumorbearing bones compared with sham mice (data not shown). In agreement with previous in vivo studies, anti-NGF therapy had no effect on disease progression as measured by tumor-induced bone destruction/remodeling, tumor growth within or outside the marrow space, and number of cancer cell colonies (Halvorson et al., 2005; Sevcik et al., 2005).

To assess whether the observed sprouting correlates with increasing cancer pain, and to determine whether anti-NGF therapy attenuates this pain, pain behaviors were analyzed in prostate tumor-bearing mice treated with vehicle, early/acute anti-NGF, early/sustained anti-NGF, and late/acute anti-NGF, and compared with sham animals treated with vehicle. When anti-NGF was acutely administered at day 10 after tumor injection, pain behaviors were reduced by $\sim 40 \%$ at day 12 , whereas when early/sustained administration of anti-NGF was begun and sustained from day 10 to 26, pain behaviors were reduced significantly compared with tumorbearing mice treated with vehicle from day 12 to day 26 after tumor injection. At the day of euthanasia (day 26 after tumor injection), the pain behaviors in these animals were reduced by $60 \%$ as compared to tumor-bearing mice treated with vehicle. In contrast, when antiNGF was first administered at day 24 and pain behaviors were assessed at day 26 there was only a relatively small and nonsignificant reduction in pain-related behaviors (Fig. 6C).

\section{Discussion}

Prostate cancer growth, formation of tumor colonies, and remodeling of bone

Prostate cancer is the most commonly diagnosed cancer in males and the second leading cause of death from cancer in men (Jemal et al., 2009). In the United States, it was estimated that 200,000 new cases and 28,000 deaths from prostate cancer will occur in 2009 (Jemal et al., 2009). Bone is by far the most common site for prostate cancer metastasis and postmortem studies have shown that $70-100 \%$ of patients that have died from prostate cancer have evidence of metastatic bone disease (Bubendorf et al., 2000; Tang and Hicks, 2010). Prostate tumor growth in bone frequently results in both ongoing and breakthrough bone cancer pain, hypercalcemia, anemia, increased susceptibility to infection, skeletal fractures, compression of the spinal cord, spinal instability and decreased mobility; all of which compromise the patient's survival and quality of life (Berruti et al., 2000; Weinfurt et al., 2005; Coleman, 2006, 2008; DePuy et al., 2007).

The prostate model of bone cancer used here appears to closely resemble the tumor growth and bone remodeling observed in humans. Thus, following injection and confinement of prostate tumor cells into the mouse femur, there is a highly stereotypic tumor-induced growth and formation of woven bone within the marrow space, similar to that observed in humans with prostate cancer metastases

to bone (Rajarubendra et al., 2010; Tang

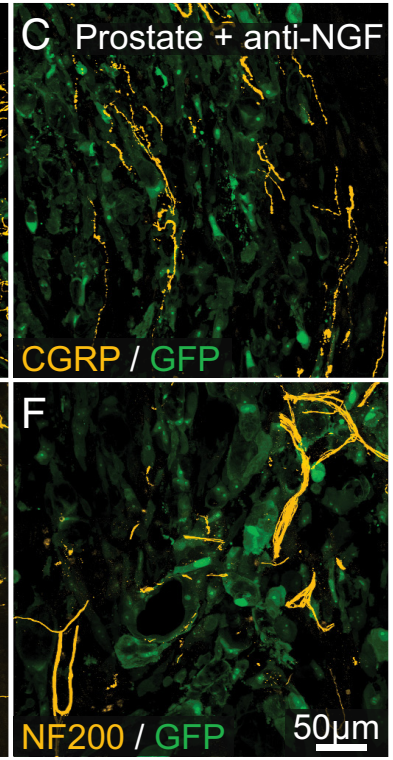

Figure 5. Preventive sequestration of NGF reduces prostate cancer-induced sprouting of $\mathrm{CGRP}^{+}$and NF200 ${ }^{+}$sensory nerve fibers. $\boldsymbol{A}-\boldsymbol{F}$, In sham-operated mice (needle placement + injection of culture medium) there is a very regular innervation of the bone marrow by $\mathrm{CGRP}^{+}\left(\boldsymbol{A}\right.$, orange) and NF200 ${ }^{+}$nerve fibers ( $\boldsymbol{D}$, yellow). As prostate cancer cells (which are transfected with green fluorescent protein: GFP, green) grow within the bone marrow and form small colonies of cancer cells, by $26 \mathrm{~d}$ after injection there is a dramatic sprouting of $\mathrm{CGRP}^{+}(\boldsymbol{B})$ and $\mathrm{NF}_{200}{ }^{+}(\boldsymbol{E})$ nerve fibers within or surrounding these colonies of prostate cancer cells. Preventive sequestration of NGF (mAb911, $10 \mathrm{mg} / \mathrm{kg}$, i.p., given at days 10, 15, 20, and 25 after cell injection) significantly reduces the pathological tumor-induced sprouting and reorganization of sensory $\mathrm{CGRP}^{+}(\boldsymbol{C})$ and NF200 ${ }^{+}(\boldsymbol{F})$ nerve fibers. Images were acquired at the metaphyseal region of the bone marrow and were projected from 40 optical sections at $0.5 \mu \mathrm{m}$ intervals. 

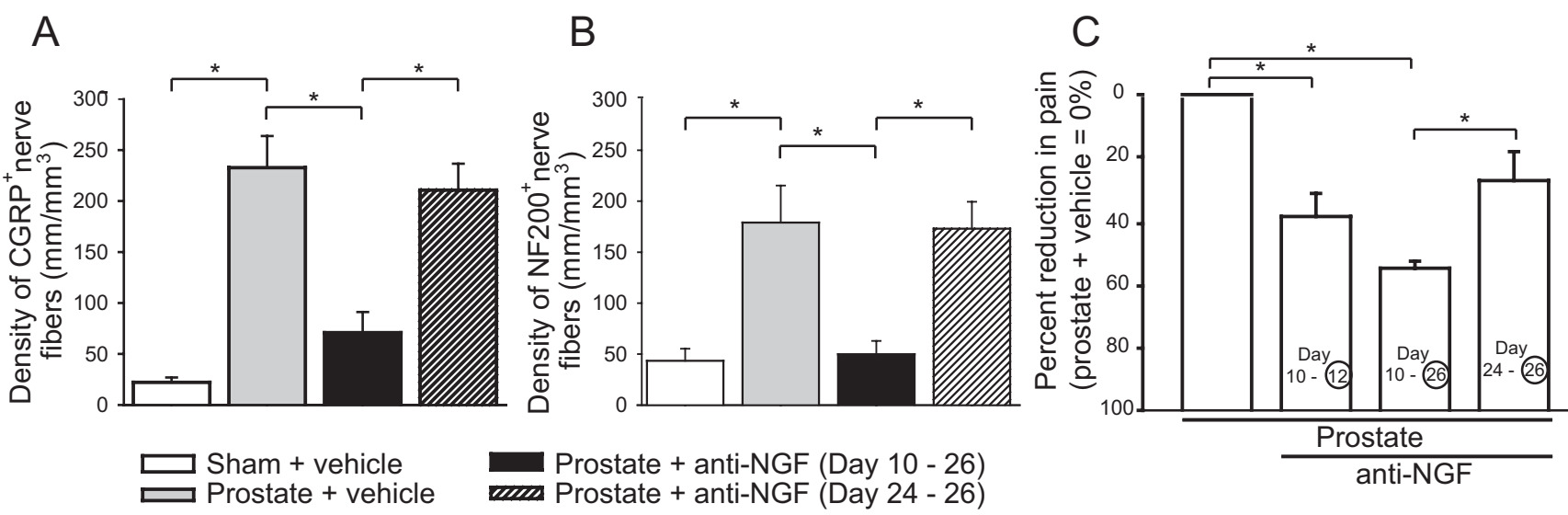

Behavior performed on the circled day

Figure 6. Preventive administration of NGF sequestering therapy reduces tumor-induced nerve sprouting of $\mathrm{GRP}^{+}$and $\mathrm{NF} 200^{+}$nerve fibers as well as bone cancer pain-related behaviors. $A-C$, At day 26 after prostate cancer cell injection, the density of $\mathrm{CGRP}^{+}(\boldsymbol{A})$ and $\mathrm{NF}_{200}{ }^{+}(\boldsymbol{B})$ nerve fibers in the cancer cell colonies is significantly greater in prostate cancer + vehicle-treated mice compared with sham + vehicle-treated mice. This tumor-induced nerve sprouting is significantly attenuated by early/sustained administration $(10 \mathrm{mg} / \mathrm{kg}, \mathrm{i} . \mathrm{p} .$, given at days $10,15,20$ and 25 after cell injection), but not by late/acute (10 mg/kg, i.p., given at day 24 after cancer cell injection) administration of anti-NGF. In accordance with the present results demonstrating that anti-NGF blocks nerve sprouting, this therapy significantly reduces the tumor-induced flinches if it is administered before sprouting occurs with an early/acute treatment (day 10-12), or early/sustained treatment (days 10, 15, 20, and 25) (C). In contrast, anti-NGF administered at late time points (day 24-26), when nerve sprouting has already occurred, does not produce a significant effect (C). Each point or bar represents the mean \pm SEM. Brackets indicate the groups being compared. ${ }^{*} p<0.05$. Imaging acquisition, imaging analysis, and behavioral analysis were performed in a blinded fashion.

and Hicks, 2010). These osteoblastic lesions appear to be driven by multiple, small colonies of highly vascularized prostate cancer cells that are separated from each other by extensive matrices of newly formed woven bone (Tang and Hicks, 2010). This pattern of extensive bone formation is in sharp contrast to the tumor growth and bone remodeling that is observed when primarily osteolytic tumors (such as sarcoma) are injected into the femur (Schwei et al., 1999; Sevcik et al., 2004). Thus, whereas sarcoma cells destroy bone and begin to undergo necrosis in $<2$ weeks after tumor injection (Sevcik et al., 2004), at 4 weeks after tumor injection the canine prostate cancer cells continue to grow in small separate colonies of tumor cells and the individual tumor cells show no evidence of necrosis. Furthermore these cancer cells remain highly vascularized by the typical, disorganized capillaries seen in many other tumor types (Fukumura and Jain, 2007). These data suggest that this prostate model has the potential to not only provide clinically useful insight into the mechanisms that generate and maintain prostate cancer-induced bone pain, but also the factors that drive prostate tumor growth and bone remodeling.

\section{Prostate tumor-induced sprouting and remodeling of sensory nerve fibers}

While the field of cancer pain research has made progress in beginning to understand what drives ongoing cancer pain, a major unanswered question is whether there is something fundamentally different between the mechanisms that drive ongoing versus breakthrough cancer pain. One possibility is that with time, the tumor environment induces a pathological sprouting and remodeling of sensory nerve fibers and that this newly formed substrate drives severe cancer pain. Clearly there is precedent for this as previous studies have shown that inappropriate remodeling of sensory nerve fibers can give rise to hyperalgesia, allodynia, and spontaneous ectopic discharges that are perceived as highly painful in humans (Lindqvist et al., 2000; Jänig and Baron, 2003; Black et al., 2008; Ceyhan et al., 2009).

To examine this possibility we focused on $\mathrm{CGRP}^{+}$and $\mathrm{NF}_{200}{ }^{+}$sensory nerve fibers, as others have suggested that nerve fibers innervating bone have a morphology and conduction velocities of unmyelinated and thinly myelinated nerve fibers (Ivanusic et al., 2006; Mahns et al., 2006) and that bone is only primarily innervated by nociceptors (Inman and Saunders, 1944). In the present study we report for the first time that in advanced cancer, sensory nerve fibers $\left(\mathrm{CGRP}^{+}\right.$and NF200 $\left.{ }^{+}\right)$undergo a pathological reorganization as evidenced by the dense and highly disorganized appearance of these nerve fibers. It

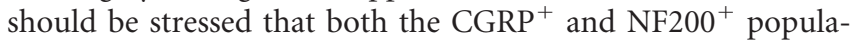
tions of sprouting nerve fibers were almost exclusively found within the tumor colonies in the marrow. These prostate tumor colonies were characterized by the presence of $\mathrm{GFP}^{+}$prostate tumor cells, $\mathrm{CD}_{68}{ }^{+}$tumor-associated macrophages, $\mathrm{CD} 31^{+}$endothelial cells, and a plethora of as yet to be characterized stromal cells and surrounding woven bone.

To further define the phenotype of the nerve fibers that undergo sprouting, we also examined whether these nerve fibers expressed TrkA and found that the great majority of sprouting $\mathrm{CGRP}^{+}$and NF200 ${ }^{+}$nerve fibers did indeed express TrkA. Interestingly, the signal/noise ratio of TrkA in the newly sprouted fibers within the tumor colonies appeared to be significantly higher than in $\operatorname{TrkA}^{+}$nerve fibers in normal marrow space. The most parsimonious explanation for this increase in TrkA staining is that there was a significant upregulation of TrkA in nerve fibers near the tumor colonies, as a similar upregulation has been reported in sensory nerve fibers near sites of inflammation (di Mola et al., 2000). These newly sprouted $\operatorname{TrkA}^{+}$nerve fibers also expressed high levels of GAP43. As GAP43 has been shown to be involved in nerve sprouting and regeneration in both the central and peripheral nervous systems (Denny, 2006), these data suggest that it is primarily CGRP ${ }^{+}$and $\mathrm{NF}_{200}{ }^{+}$nerve fibers, coexpressing both TrkA and GAP43, that undergo a remarkable sprouting and reorganization in response to nearby tumor growth.

NGF drives ectopic sensory nerve fiber sprouting and pain To begin to address what factor(s) might be involved in driving the observed sprouting and remodeling of sensory nerve fibers, in this study we focused on NGF as nearly all the sprouting CGRP ${ }^{+}$ 
and NF200 ${ }^{+}$nerve fibers expressed TrkA, and TrkA is the cognate receptor for NGF. Additionally, previous reports have demonstrated that even in the adult, NGF can induce marked sprouting of TrkA ${ }^{+}$sensory nerve fibers (Pezet and McMahon, 2006). Using a mouse monoclonal antibody against NGF (anti-NGF), that is highly specific for NGF and shows virtually no cross-reactivity to other neurotrophins, we provided evidence that early/sustained administration of anti-NGF results in a marked reduction of sprouting by CGRP ${ }^{+}$and $\mathrm{NF} 200^{+}$nerve fibers in the tumorbearing bone. Whether NGF drives this sprouting through binding to the TrkA or p75 receptor is yet unknown. However, previous studies suggest that TrkA is more involved in driving sprouting (Gallo et al., 1997), while p75 is more involved in apoptosis (Bamji et al., 1998).

In light of the remarkable sprouting induced by prostate cancer cells in bone, two important and clinically relevant questions are, what is the source of NGF that is driving the sprouting of sensory nerve fibers and is this sprouting only observed in tumor cells that express NGF? Interestingly, using highly sensitive RTPCR analysis, we were not able to find detectable levels of mRNA coding for NGF in this canine prostate cancer cell line (using primers to the canine sequence of NGF; supplemental Table 1, available at www.jneurosci.org as supplemental material). These data strongly suggest that it is not the tumor cells that are the major source of NGF but rather it is the tumor-associated inflammatory, immune, and/or stromal cells. This possibility is supported by studies that have shown that macrophages, endothelial cells, T-lymphocytes, and fibroblasts can express significant levels of NGF (Lindsay et al., 2005; Nassenstein et al., 2006; Pezet and McMahon, 2006). Additionally, in most cancers these and other tumor-associated stromal cells comprise $10-80 \%$ of the mass of a tumor (Key, 1983; Normann, 1985; Bingle et al., 2002). In the present study using the ratio of DAPI (which stains all nuclei)/GFP ${ }^{+}$tumor cells in the prostate tumor colonies, $>90 \%$ of the cells in the tumor colonies are stromal rather than cancer cells. These data suggest that therapies aimed at blocking NGF/TrkA-induced ectopic nerve sprouting should be useful in any cancer where either the tumor or tumor stromal cells are expressing and releasing significant amounts of NGF.

Here it is shown that early administration of anti-NGF, at a time when the pain and tumor-induced bone remodeling are first evident, can block the ectopic sprouting and pathological reorganization of sensory nerve fibers that in other nonmalignant diseases has been shown to generate and maintain chronic pain. This concept, that optimal analgesic efficacy will be achieved when the therapy is administered early, before the development of a chronic pain state, is known as preventive analgesia. Although the concept of preventive analgesia is both intuitive and appealing, its scientific basis is largely unknown. For example, whereas preventive analgesia has been demonstrated in animal models, with experiments showing that blockade of early pain reduces synaptic strengthening of pain circuits in the spinal cord and brain (Woolf and Chong, 1993), human clinical trials have been equivocal (Ballantyne, 2001; Pogatzki-Zahn and Zahn, 2006). Importantly, the present study identifies a clear and understandable mechanism by which the blockade of NGF or TrkA could produce a preventive analgesic effect in a chronic pain state.

\section{References}

Ballantyne JC (2001) Pre-emptive analgesia: an unsolved problem. Curr Opin Anesthesiol 14:499-504.

Bamji SX, Majdan M, Pozniak CD, Belliveau DJ, Aloyz R, Kohn J, Causing CG, Miller FD (1998) The p75 neurotrophin receptor mediates neuro- nal apoptosis and is essential for naturally occurring sympathetic neuron death. J Cell Biol 140:911-923.

Berruti A, Dogliotti L, Bitossi R, Fasolis G, Gorzegno G, Bellina M, Torta M, Porpiglia F, Fontana D, Angeli A (2000) Incidence of skeletal complications in patients with bone metastatic prostate cancer and hormone refractory disease: predictive role of bone resorption and formation markers evaluated at baseline. J Urol 164:1248-1253.

Bingle L, Brown NJ, Lewis CE (2002) The role of tumour-associated macrophages in tumour progression: implications for new anticancer therapies. J Pathol 196:254-265.

Black JA, Nikolajsen L, Kroner K, Jensen TS, Waxman SG (2008) Multiple sodium channel isoforms and mitogen-activated protein kinases are present in painful human neuromas. Ann Neurol 64:644-653.

Boyle P, Levin B, eds (2008) World cancer report 2008. Lyon: International Agency for Research on Cancer.

Bubendorf L, Schöpfer A, Wagner U, Sauter G, Moch H, Willi N, Gasser TC, Mihatsch MJ (2000) Metastatic patterns of prostate cancer: an autopsy study of 1,589 patients. Hum Pathol 31:578-583.

Ceyhan GO, Bergmann F, Kadihasanoglu M, Altintas B, Demir IE, Hinz U, Müller MW, Giese T, Büchler MW, Giese NA, Friess H (2009) Pancreatic neuropathy and neuropathic pain-a comprehensive pathomorphological study of 546 cases. Gastroenterology 136:177-186 el.

Coleman RE (2006) Clinical features of metastatic bone disease and risk of skeletal morbidity. Clin Cancer Res 12:6243s-6249s.

Coleman RE (2008) Risks and benefits of bisphosphonates. Br J Cancer 98:1736-1740.

de Mos M, de Bruijn AG, Huygen FJ, Dieleman JP, Stricker BH, Sturkenboom MC (2007) The incidence of complex regional pain syndrome: a population-based study. Pain 129:12-20.

Denny JB (2006) Molecular mechanisms, biological actions, and neuropharmacology of the growth-associated protein GAP-43. Curr Neuropharmacol 4:293-304.

DePuy V, Anstrom KJ, Castel LD, Schulman KA, Weinfurt KP, Saad F (2007) Effects of skeletal morbidities on longitudinal patient-reported outcomes and survival in patients with metastatic prostate cancer. Support Care Cancer 15:869-876.

di Mola FF, Friess H, Zhu ZW, Koliopanos A, Bley T, Di Sebastiano P, Innocenti P, Zimmermann A, Büchler MW (2000) Nerve growth factor and Trk high affinity receptor (TrkA) gene expression in inflammatory bowel disease. Gut 46:670-679.

Dy SM, Asch SM, Naeim A, Sanati H, Walling A, Lorenz KA (2008) Evidence-based standards for cancer pain management. J Clin Oncol 26:3879-3885.

Fukumura D, Jain RK (2007) Tumor microvasculature and microenvironment: targets for anti-angiogenesis and normalization. Microvasc Res 74:72-84.

Gallo G, Lefcort FB, Letourneau PC (1997) The trkA receptor mediates growth cone turning toward a localized source of nerve growth factor. J Neurosci 17:5445-5454.

Halvorson KG, Kubota K, Sevcik MA, Lindsay TH, Sotillo JE, Ghilardi JR, Rosol TJ, Boustany L, Shelton DL, Mantyh PW (2005) A blocking antibody to nerve growth factor attenuates skeletal pain induced by prostate tumor cells growing in bone. Cancer Res 65:9426-9435.

Hongo JS, Laramee GR, Urfer R, Shelton DL, Restivo T, Sadick M, Galloway A, Chu H, Winslow JW (2000) Antibody binding regions on human nerve growth factor identified by homolog- and alanine-scanning mutagenesis. Hybridoma 19:215-227.

Hwang SS, Chang VT, Kasimis B (2003) Cancer breakthrough pain characteristics and responses to treatment at a VA medical center. Pain 101:55-64.

Inman VT, Saunders JB (1944) Referred pain from skeletal structures. J Nerve Ment Dis 99:660-667.

Ivanusic JJ, Mahns DA, Sahai V, Rowe MJ (2006) Absence of large-diameter sensory fibres in a nerve to the cat humerus. J Anat 208:251-255.

Jänig W, Baron R (2003) Complex regional pain syndrome: mystery explained? Lancet Neurol 2:687-697.

Jemal A, Siegel R, Ward E, Hao Y, Xu J, Thun MJ (2009) Cancer statistics, 2009. CA Cancer J Clin 59:225-249.

Jimenez-Andrade JM, Mantyh WG, Bloom AP, Xu H, Ferng AS, Dussor G, Vanderah TW, Mantyh PW (2010) A phenotypically restricted set of primary afferent nerve fibers innervate the bone versus skin: therapeutic opportunity for treating skeletal pain. Bone 46:306-313. 
Key ME (1983) Macrophages in cancer metastases and their relevance to metastatic growth. Cancer Metastasis Rev 2:75-88.

Kivelä R, Havas E, Vihko V (2007) Localisation of lymphatic vessels and vascular endothelial growth factors- $\mathrm{C}$ and $-\mathrm{D}$ in human and mouse skeletal muscle with immunohistochemistry. Histochem Cell Biol 127:31-40.

Lindqvist A, Rivero-Melian C, Turan I, Fried K (2000) Neuropeptide- and tyrosine hydroxylase-immunoreactive nerve fibers in painful Morton's neuromas. Muscle Nerve 23:1214-1218.

Lindsay TH, Jonas BM, Sevcik MA, Kubota K, Halvorson KG, Ghilardi JR, Kuskowski MA, Stelow EB, Mukherjee P, Gendler SJ, Wong GY, Mantyh PW (2005) Pancreatic cancer pain and its correlation with changes in tumor vasculature, macrophage infiltration, neuronal innervation, body weight and disease progression. Pain 119:233-246.

Mach DB, Rogers SD, Sabino MC, Luger NM, Schwei MJ, Pomonis JD, Keyser CP, Clohisy DR, Adams DJ, O'Leary P, Mantyh PW (2002) Origins of skeletal pain: sensory and sympathetic innervation of the mouse femur. Neuroscience 113:155-166.

Mahns DA, Ivanusic JJ, Sahai V, Rowe MJ (2006) An intact peripheral nerve preparation for monitoring the activity of single, periosteal afferent nerve fibres. J Neurosci Methods 156:140-144.

Martin CD, Jimenez-Andrade JM, Ghilardi JR, Mantyh PW (2007) Organization of a unique net-like meshwork of CGRP+ sensory fibers in the mouse periosteum: implications for the generation and maintenance of bone fracture pain. Neurosci Lett 427:148-152.

Mercadante S, Arcuri E (1998) Breakthrough pain in cancer patients: pathophysiology and treatment. Cancer Treat Rev 24:425-432.

Mercadante S, Villari P, Ferrera P, Casuccio A (2004) Optimization of opioid therapy for preventing incident pain associated with bone metastases. J Pain Symptom Manage 28:505-510.

Meuser T, Pietruck C, Radbruch L, Stute P, Lehmann KA, Grond S (2001) Symptoms during cancer pain treatment following WHO-guidelines: a longitudinal follow-up study of symptom prevalence, severity and etiology. Pain 93:247-257.

Nassenstein C, Schulte-Herbrüggen O, Renz H, Braun A (2006) Nerve growth factor: the central hub in the development of allergic asthma? Eur J Pharmacol 533:195-206.

Normann SJ (1985) Macrophage infiltration and tumor progression. Cancer Metastasis Rev 4:277-291.

Odaka C, Morisada T, Oike Y, Suda T (2006) Distribution of lymphatic vessels in mouse thymus: immunofluorescence analysis. Cell Tissue Res 325:13-22.

Peters CM, Ghilardi JR, Keyser CP, Kubota K, Lindsay TH, Luger NM, Mach DB, Schwei MJ, Sevcik MA, Mantyh PW (2005) Tumor-induced injury of primary afferent sensory nerve fibers in bone cancer pain. Exp Neurol 193:85-100.

Pezet S, McMahon SB (2006) Neurotrophins: mediators and modulators of pain. Annu Rev Neurosci 29:507-538.
Pogatzki-Zahn EM, Zahn PK (2006) From preemptive to preventive analgesia. Curr Opin Anaesthesiol 19:551-555.

Portenoy RK, Hagen NA (1990) Breakthrough pain: definition, prevalence and characteristics. Pain 41:273-281.

Rajarubendra N, Bolton D, Lawrentschuk N (2010) Diagnosis of bone metastases in urological malignancies-an update. Urology. Advance online publication. Retrieved May 27, 2010. doi:10.1016/j.urology.2009.12.050.

Rigaud J, Tiguert R, Le Normand L, Karam G, Glemain P, Buzelin JM, Bouchot O (2002) Prognostic value of bone scan in patients with metastatic prostate cancer treated initially with androgen deprivation therapy. J Urol 168:1423-1426.

Sabino MA, Ghilardi JR, Jongen JL, Keyser CP, Luger NM, Mach DB, Peters CM, Rogers SD, Schwei MJ, de Felipe C, Mantyh PW (2002) Simultaneous reduction in cancer pain, bone destruction, and tumor growth by selective inhibition of cyclooxygenase-2. Cancer Res 62:7343-7349.

Schwei MJ, Honore P, Rogers SD, Salak-Johnson JL, Finke MP, Ramnaraine ML, Clohisy DR, Mantyh PW (1999) Neurochemical and cellular reorganization of the spinal cord in a murine model of bone cancer pain. J Neurosci 19:10886-10897.

Sevcik MA, Luger NM, Mach DB, Sabino MA, Peters CM, Ghilardi JR, Schwei MJ, Röhrich H, De Felipe C, Kuskowski MA, Mantyh PW (2004) Bone cancer pain: the effects of the bisphosphonate alendronate on pain, skeletal remodeling, tumor growth and tumor necrosis. Pain 111:169-180.

Sevcik MA, Ghilardi JR, Peters CM, Lindsay TH, Halvorson KG, Jonas BM, Kubota K, Kuskowski MA, Boustany L, Shelton DL, Mantyh PW (2005) Anti-NGF therapy profoundly reduces bone cancer pain and the accompanying increase in markers of peripheral and central sensitization. Pain 115:128-141.

Shelton DL, Zeller J, Ho WH, Pons J, Rosenthal A (2005) Nerve growth factor mediates hyperalgesia and cachexia in auto-immune arthritis. Pain $116: 8-16$

Tang P, Hicks DG (2010) The histopathology of skeletal metastases. In: Bone cancer: progression and therapeutic approaches (Heymann D, ed), pp 243-250. New York: Elsevier.

Weinfurt KP, Li Y, Castel LD, Saad F, Timbie JW, Glendenning GA, Schulman KA (2005) The significance of skeletal-related events for the healthrelated quality of life of patients with metastatic prostate cancer. Ann Oncol 16:579-584.

Woolf CJ, Chong MS (1993) Preemptive analgesia-treating postoperative pain by preventing the establishment of central sensitization. Anesth Analg 77:362-379.

Yen LD, Bennett GJ, Ribeiro-da-Silva A (2006) Sympathetic sprouting and changes in nociceptive sensory innervation in the glabrous skin of the rat hindpaw following partial peripheral nerve injury. J Comp Neurol 495: 679-690. 